\title{
Orta-Ağır Bronkopulmoner Displazide Tek Merkez Deneyimi: Antenatal ve Postnatal Risk Faktörleri
}

\author{
Antenatal and Postnatal Risk Factors for Bronchopulmonary \\ dysplasia: Single-center Experience \\ Buse ÖZER BEKMEZ¹, Mehmet BÜYÜKTIRYAKi², Fatma Nur SARI ${ }^{3}$, Evrim ALYAMAÇ DIZDAR³, \\ Cüneyt TAYMAN ${ }^{3}$, Şerife Suna OĞUZ ${ }^{3}$
}

'Sarıyer Hamidiye Etfal Eğitim ve Araștırma Hastanesi, Yenidoğan Yoğun Bakım Ünitesi, İstanbul, Türkiye

${ }^{2}$ Medipol Üniversitesi Tıp Fakültesi Hastanesi, Yenidoğan Yoğun Bakım Ünitesi, İstanbul, Türkiye

${ }^{3}$ Ankara Șehir Hastanesi, Yenidoğan Yoğun Bakım Ünitesi, Ankara, Türkiye

\section{ÖZ}

Amaç: Bronkopulmoner displazi (BPD), çok düşük doğum ağırlıkı her üç bebekten birini etkileyen uzun dönem ciddi olumsuz sonuçları olan bir prematüre morbiditesidir. Bu çalışmada orta-ağır BPD için antenatal ve postnatal risk faktörlerini araştırmayı amaçladık.

Gereç ve Yöntemler: Tek merkezli retrospektif kohort çalışmada Ocak 2014-Aralık 2018 tarihleri arasında doğan <32 hafta ve <1500 g bebekler dahil edildi. Orta-ağır BPD tanılı hastalar çalışma grubunu, hafif BPD ve BPD tanısı olmayan hastalar kontrol grubunu oluşturdu. Her iki grup antenatal ve postnatal özellikleri açısından karşılaştırıldı.

Bulgular: 626 bebekten oluşan kohortun ortalama gestasyonel yaş ve doğum ağıllı̆ı sırasıyla $28 \pm 1.4$ hafta ve $1084 \pm 225$ g'dı. Orta-ağır BPD tanılı 97 bebeğin (\%15.4) ortalama gestasyonel yaş ve doğum ağırlıkları, kontrol grubuna

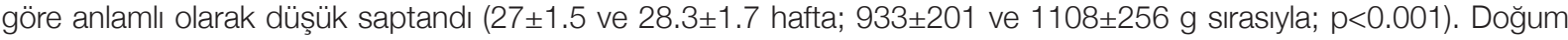
salonunda ileri canlandırma (OR 2.64, Cl [1.57-4.4]), gestasyonel yaş (OR $0.80 \mathrm{Cl}$ [0.67-0.95]), hemodinamik anlamlı patent duktus arteriozus (haPDA) (OR $1.78 \mathrm{Cl}$ [1.05-3.03]) ve geç tam enteral beslenme (OR 1.05 Cl [1.02-1.08]) orta/ ağır BPD ile ilişkili bulundu.

Sonuç: Doğum salonunda ileri canlandırma, düşük gestasyon haftası, haPDA ve geç tam enteral beslenme BPD ile ilişkili bulunmuştur. Ancak tam enteral beslenmeye geçiş süresi ve haPDA ile BPD ilişkisinin neden sonuç mu, yoksa BPD’ye gidiş sürecindeki hastalık durumunun bir parçası olup olmadığının ortaya çıkarılması için geniş çaplı prospektif çalışmalara ihtiyaç olduğu düşünülmüştür.

Anahtar Sözcükler: Bronkopulmoner displazi, Enteral beslenme, Prematürite

\begin{abstract}
Objective: Bronchopulmonary dysplasia (BPD) is the chronic lung disease of prematurity that affects a substantial proportion of extremely preterm infants. We aimed to find out the antenatal and postnatal risk factors for BPD in a largescale cohort of preterm infants.

Material and Methods: Records of preterm infants born $<32$ gestational weeks and $<1500 \mathrm{~g}$ were included in this single-center retrospective study that was performed between January 2014 and December 2018. While babies with moderate and severe BPD constituted the study group, the control group included those with mild BPD and without BPD. Groups were compared in terms of antenatal and postnatal risk factors.

Results: In the final analysis, data of 626 infants were recorded. The mean gestational age and birth weight of the whole cohort were $28 \pm 1.4$ weeks and $1084 \pm 225$ g, respectively. Ninety-seven (15.4\%) infants in the study group had
\end{abstract}

(1)

0000-0002-0397-1369 :ÖZER BEKMEZ B 0000-0001-8937-4671:BÜYÜKTIRYAKI M 0000-0003-4643-7622:SARI FN 0000-0001-8956-0917 : ALYAMACG DIZDARE OOO0-0001-8956-0917: :ALYAMAC D 0000-0003-4643-7622 :OĞUZ ȘS

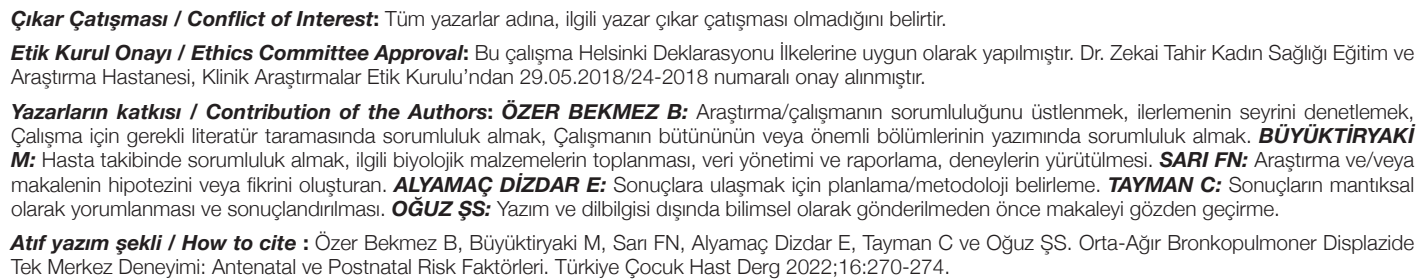

Yazışma Adresi / Correspondence Address:
Geliş tarihi/ Received : :29.06.2021 Kabul tarihi / Accepted : 13.09.2021 Elektronik yayın tarihi : 16.11 .2021 Online published

DOI: 10.12956/tchd.959157 
significantly lower gestational age and birth weight compared to those in the control group ( $27 \pm 1.5$ vs $28.3 \pm 1.7$ weeks, and $933 \pm 201$ vs $1108 \pm 256$ g respectively, $\mathrm{p}<0.05)$. Extensive resuscitation in the delivery room (OR 2.64, $\mathrm{Cl}[1.57-4.4])$, low gestational age (OR 0.80 $\mathrm{Cl}$ [0.67-0.95]), hemodynamically significant patent ductus arteriosus (hsPDA) (OR 1.78 Cl [1.05-3.03]) and delayed full enteral feeding (OR $1.05 \mathrm{Cl}$ [1.02-1.08]) were associated with a higher rate of moderate-to-severe BPD.

Conclusion: Large-scale randomized controlled trials are warranted to elucidate whether the association of hsPDA and delayed full enteral feeding with BPD is a real cause and effect relationship or a component of illness state during the process of evolving BPD.

Key Words: Bronchopulmonary dysplasia, Enteral nutrition, Prematurity

\section{Giriş}

Bronkopulmoner displazi (BPD), prematürenin multifaktoriyel etiyolojiyle karakterize kronik akciğer hastalığıdır (1). İlk kez 1967 yılında Northway ve arkadaşları tarafından tanımlanan ve daha büyük prematüre bebeklerde görülen, ön planda kistik değişiklikler ve heterojen havalanma ile karakterize eski BPD yerini daha düşük hafta bebeklerde alveolar ve vasküler gelişim bozukluğunun görüldüğü yeni BPD’ye bırakmıştır (1,2). Antenatal kortikosteroid uygulamaları, yaygın kafein kullanımı ve minimal invaziv surfaktan uygulamaları gibi güncel yaklaşımları da içeren tıbbi hizmetlerin iyileşmesi ile birlikte, aşırı preterm bebeklerin yaşam süresinin artması beklenenin aksine BPD oranlarında bir azalmaya neden olmamış ve BPD sıklığı aynı kalmıştır (3). BPD günümüzde hala çok düşük doğum ağırlıklı bebeklerin \%20-40'ını etkilemeye devam etmektedir (4). Bu yeni tip BPD gelişimine neden olan risk faktörleri araştırmacıların ilgisini çekmiş ve etiyolojisini aydınlatmaya yönelik birçok çalışma yapılmıştır.

Genetik yatkınlığın patogenezde önemli bir rol oynadığı gerçeği yanında, birçok antenatal ve postnatal faktör etiyolojide suçlanmıştır (5). BPD gelişiminde en önemli tetikleyici henüz kanaliküler evreden sakküler evreye geçmekte olan akciğer gelişiminin, preterm doğum sonucu duraklaması ve hasarlanmasıdır (5). Bunun yanında intrauterin büyüme kısıtıı̆̆ı, koryoamniyonit, preeklampsi, annenin sigara kullanımı BPD için bilinen antenatal predispozan faktörlerden bazılarıdır (3). Bebeğin ilk soluğunu alması ile birlikte BPD gelişimini etkileyebilecek postnatal olaylar zinciri gündeme gelmektedir. BPD ve diğer morbiditeler arasında neden sonuç ilişkisi kurmak oldukça zor olsa da invaziv solunum desteği, ek oksijen kullanımı, sepsis, patent duktus arteriozus ve ekstrauterin büyüme kısıtılığının BPD ile ilişkili olabileceği düşünülmektedir (3).

Bu çalışmada, geniş bir kohortta orta ve ağır BPD ile ilişkili antenatal ve postnatal faktörlerin ortaya konulması amaçlanmıştır.

\section{GEREÇ ve YÖNTEMLER}

Bu tek merkezli retrospektif kohort çalışmaya, Ocak 2014-Aralık 2018 tarihleri arasında doğan 32 gestasyon hafta ve doğum ağırlığı 1500 g ve altında olan hastalar dahil edildi. Orta ve ağır
BPD tanısı alan hastalar çalışma grubunu oluşturmaktayken, hafif BPD tanılı hastalar ile BPD tanısı almayan hastalar kontrol grubunu oluşturdu. Major konjenital veya kromozomal anomalisi olanlar ile dosya kayıtlarından verilerine ulaşılmayan hastalar çalışma dışı bırakıldı. Çalışma için Dr. Zekai Tahir Kadın Sağlığı Eğitim ve Araştırma Hastanesi, Klinik Araştırmalar Etik Kurulu'ndan 29.05.2018/24-2018 numaralı onay alınmıştır.

BPD tanısı ve sınıflaması, Jobe AH ve Bancalari E'nin 2001 yılında Ulusal Sağlık Çalıştayı'nda önerdiği sınıflamaya göre yapılmıştır (2). Gebelik haftası 32 hafta bebeklerde hafif BPD; en az 28 gün boyunca ek $\mathrm{O} 2$ tedavisi alan ve düzeltilmiş 36 hafta veya taburculuk sırasında ek $\mathrm{O} 2$ ihtiyacı olmaması olarak tanımlanmıştır (2). Orta ve ağır BPD ise postmentrüel 36. haftada ya da taburculuk sırasında $<\% 30$ ek O2 gereksinimi ve z\%30 ek O2 veya pozitif basınçlı ventilasyon gereksinimi olarak tanımlanmıştır (2).

Hasta kayıtlarından erken membran rüptürü ve süresi, klinik ve/ veya histolojik koryoamniyonit, preeklampsi, diyabetes mellitus, hipertansiyon ve çoğul gebelik varlığını içeren maternal veriler elde edildi.

Neonatal özellikler, gestasyon yașı, doğum ağırlığı, doğum şekli, cinsiyet, doğum haftasına göre düşük doğum ağırlığı, antenatal kortikosteroid uygulaması vb demografik özellikler yanında, doğum salonunda ileri canlandırma, respiratuar distres sendromu, surfaktan doz ve sayısı, solunum desteği suresi (invaziv mekanik ventilasyon, noninvaziv solunum desteği ve ek O2 suresi), erken ve geç neonatal sepsis, hemodinamik anlamlı patent duktus arteriosus (haPDA), haPDA nedeniyle medikal tedavi ve/veya ligasyon uygulanması, evre 3-4 intraventriküler kanama (6), periventriküler lökomalazi, doğum ağılığına ulaşılan gün, tam enteral beslenme günü, taburculuk günü ve kilosu, beslenme intoleransı varlığı, nekrotizan enterokolit (modifiye Bell sınıflamasına göre $\geq$ Evre 2b) (7) spontan intestinal perforasyon, prematüre osteopenisi, prematüre retinopatisi (lazer fotokoagulasyon gerektiren) ve mortalite verileri retrospektif olarak hasta kayıtlarından not edildi.

Doğum salonunda ileri canlandırma; hava yolunu temizleme, taktil uyaran verme ve pozitif basınçlı ventilasyona ilaveten endotrakeal entübasyon, göğüs kompresyonu ve/veya ilaç kullanımı olarak tanımlanmıştır.

Beslenme intoleransı tanısı safralı kusma veya bir önceki beslenme volümünün >\%50 gastrik rezidü saptanması; batın 
hassasiyeti veya renk değişikliği, 24 saat içinde $\geq 3$ kusma ve sonuç olarak bebeğin beslenme planının bozulması durumu olarak tanımlanmışıı (8). haPDA tanısı, klinik ve ekokardiyografik bulgular varlığında neonatolog ve kardiyolog tarafindan konuldu. Solunum sıkıntısı, artmış oksijen veya ventilasyon intiyacı, takipne, hipoksi veya başka bir nedenle açıklanamayan apne gibi klinik bulgulara ilaveten ekokardiyografi ile tespit edilmiş geniş duktus çapı (>1.5 mm) ve artmış sol atrium:aort kökü oranı (>1.4) varlığında haPDA tanısı konuldu. haPDA tanısı konulan bebeklere farmakolojik tedavi başlandı. Medikal ajan olarak öncelikle oral ibuprofen, ibuprofen için kontrendikasyon varlığında ise intravenöz parasetamol kullanıldı. haPDA bulgularının devam etmesi durumunda klinisyenin kararı doğrultusunda aynı veya farklı ajanlar ile medikal tedavi tekrarlandı. Farmakolojik tedavilerin başarısız olması durumunda kardiyolog ve neonatolog ortak kararı ile ligasyon uygulandı.

Ünitemizde 2010 ylından beri doğum ağırlığı ve postnatal güne göre hazırlanmış parenteral nutrisyon solüsyonları kullanılmaktadır. Kliniğimizde 32 hafta ve $1500 \mathrm{~g}$ ve altında doğan tüm bebeklere en kısa süre içerisinde parenteral nutrisyon desteği başlandı, anneler süt sağma konusunda teşvik edildi ve en kısa sürede minimal trofik beslenme başlandı. Bebeklerin beslenme toleransına göre 3-5 gün minimal beslenme devam edildi.

\section{İstatistiksel analiz}

Verilerin istatistiksel analizi SPSS 22.0 programı kullanılarak yapıldı. Tanımlayıcı istatistikler ortalama \pm standart sapma, frekans dağılımı ve yüzde olarak sunuldu. Devamlı değişkenlerin normal dağlıma uygunluğu görsel (histogram ve olasillik grafikleri) ve analitik yöntemler (Kolmogorov Smirnov/ShapiroWilk Testi) kullanılarak incelendi. Kategorik değişkenlerin değerlendirilmesinde Pearson Chi-square test ve Fisher's Exact test kullanıldı. Ileri analiz için lojistik regresyon analizi kullanıldı. İstatistiksel anlamllık düzeyi $p<0.05$ olarak kabul edildi.

\section{BULGULAR}

Bu çalışmada, 626 bebeğin verisi analiz edildi. Grupların demografik özellikleri ve antenatal faktörler Tablo I'de verildi. Tüm kohortun ortalama gestasyonel yaş ve doğum ağırlığı sırasıly $28 \pm 1.4$ hafta ve $1084 \pm 225$ g'dı. Toplam 626 bebekten 97'si (\%15.4) orta-ağır BPD tanısı aldı. Orta-ağır BPD tanıı 97 bebeğin (\%15.4) ortalama gestasyonel yaş ve doğum ağırlıkları, kontrol grubuna göre anlamlı olarak düşük saptandı $(27 \pm 1.5$ ve $28.3 \pm 1.7$ hafta; $933 \pm 201$ ve $1108 \pm 256$ g sirasiyla; $\mathrm{p}<0,001)$. Preterm morbiditeleri Tablo Il'de verilmiştir. Tek varyant analizinde orta-ağır BPD için anlamlı risk faktörü olan tüm değişkenler lojistik regresyon analizi modeline dahil edildi. Doğum salonunda ileri canlandırma (OR $2.64 \mathrm{Cl}$ [1.57-4.4]), gestasyonel yaş (OR $0.80 \mathrm{Cl}$ [0.67-0.95], haPDA (OR $1.78 \mathrm{Cl}$ [1.05-3.03]) ve geç tam enteral beslenme (OR $1.05 \mathrm{Cl}$ [1.021.08]) orta/ağır BPD ile ilişkili bulundu.

\section{TARTIŞMA}

Bu çalışma sonucunda tek merkezli geniş kohortlu bir seride gestasyonel yaş, doğum salonunda ileri canlandırma, haPDA ve gecikmiş tam enteral beslenme orta-ağır BPD gelişimi ile ilişkili bulundu.

Çalışmamızda geç tam enteral beslenme lojistik regresyon analizi sonucunda BPD için risk faktörü olarak ortaya konmuştur. Öte yandan, enteral beslenmeye başlama ve doğum ağırlığına

Tablo I: Grupların demografik özellikleri.

\begin{tabular}{|c|c|c|c|}
\hline Özellik & $\begin{array}{c}\begin{array}{c}\text { Orta-Ağır BPD } \\
\mathrm{n}=97\end{array} \\
\end{array}$ & $\begin{array}{c}\text { Kontrol } \\
n=529\end{array}$ & $\mathbf{p}$ \\
\hline Gestasyonel yaş, hafta* & $27 \pm 1.5$ & $28.3 \pm 1.7$ & $<0.001$ \\
\hline Doğum ağırı̆̆ı̆, $\mathrm{g}^{*}$ & $933 \pm 201$ & $1108 \pm 256$ & $<0.001$ \\
\hline Erkek cinsiyet, $n(\%)$ & $50(51.5)$ & $267(50.5)$ & 0.47 \\
\hline Sezaryen doğum, n (\%) & $69(71)$ & $386(73)$ & 0.41 \\
\hline Antenatal kortikosteroid, n (\%) & $61(62.9)$ & $367(69.4)$ & 0.12 \\
\hline APGAR $1^{*}$ & $4 \pm 2$ & $5 \pm 1$ & $<0.001$ \\
\hline APGAR $5^{*}$ & $6 \pm 1$ & $7 \pm 1$ & $<0.001$ \\
\hline SGA, n (\%) & $76(78)$ & $460(86)$ & 0.35 \\
\hline EMR, n (\%) & $19(19.6)$ & $102(19.3)$ & 0.52 \\
\hline Histolojik koryoamniyonit, n (\%) & $13(13.4)$ & $60(11.4)$ & 0.33 \\
\hline Preeklampsi, n (\%) & $15(15)$ & $91(17.2)$ & 0.53 \\
\hline Maternal diabetes mellitus, n (\%) & $3(3)$ & $22(4)$ & 0.50 \\
\hline Çoğul gebelik, n (\%) & $22(22.7)$ & $118(22.3)$ & 0.51 \\
\hline
\end{tabular}

*Ortalama \pm standart sapma olarak verilmiştir. EMR: Erken membran rüptürü, SGA:gebelik haftasına göre düşük doğum ağırliğı. 
Tablo II: Grupların klinik özellikleri.

\begin{tabular}{|c|c|c|c|}
\hline Özellik & $\begin{array}{c}\begin{array}{c}\text { Orta-Ağır BPD } \\
\mathrm{n}=97\end{array} \\
\end{array}$ & $\begin{array}{c}\text { Kontrol } \\
\mathrm{n}=529\end{array}$ & p \\
\hline haPDA & $66(68)$ & $207(39)$ & $<0.001$ \\
\hline haPDA için farmakolojik tedavi (2 kür) & $28(28)$ & $58(11)$ & $<0.001$ \\
\hline PDA ligasyonu & $7(7)$ & $10(2)$ & 0.009 \\
\hline Surfaktan (2 doz) & $36(37)$ & $63(11.9)$ & $<0.001$ \\
\hline İnvaziv ventilasyon süresi* & $20 \pm 21$ & $3 \pm 6$ & $<0.001$ \\
\hline Non-invaziv ventilasyon süresi* & $22 \pm 12$ & $8 \pm 8$ & $<0.001$ \\
\hline Doğum odasında ileri canlandırma & $49(50)$ & $109(20)$ & $<0.001$ \\
\hline Evre 3-4 IVK & $18(18.6)$ & $29(5.5)$ & $<0.001$ \\
\hline Periventriküler lökomalazi & $25(25.8)$ & $33(6.3)$ & $<0.001$ \\
\hline Erken neonatal sepsis & $14(14.4)$ & $73(13.8)$ & 0.48 \\
\hline Geç neonatal sepsis & $38(39)$ & $128(24)$ & 0.002 \\
\hline Doğum ağırlığına ulaşma günü* & $15 \pm 4$ & $13 \pm 6$ & $<0.001$ \\
\hline Tam enteral beslenme günü* & $20 \pm 8$ & $16 \pm 7$ & $<0.001$ \\
\hline Beslenme intoleransı & $52(53.6)$ & $184(34.8)$ & $<0.001$ \\
\hline Nekrotizan enterokolit & $5(5,2)$ & $7(1.3)$ & 0.026 \\
\hline Spontan intestinal perforasyon & $4(4)$ & $7(1,3)$ & 0.075 \\
\hline Prematüre osteopenisi & $16(16,5)$ & $33(6)$ & 0.003 \\
\hline Prematüre retinopatisi & $23(22)$ & $27(5.3)$ & $<0.001$ \\
\hline Mortalite & $6(6)$ & $5(1)$ & $<0.001$ \\
\hline
\end{tabular}

*Ortalama \pm standart sapma olarak verilmiştir. Frekanslar n (\%) olarak verilmiştir. haPDA: hemodinamik anlamlı patent duktus arteriozus, iVK: intraventriküler kanama.

ulaşma günü, BPD tanilı hastalarda daha geç, beslenme intoleransı ve NEK ise anlamlı olarak daha sık görülürken regresyon analizinde bir risk faktörü olarak gösterilemedi. BPD gelişimi ile beslenme ilişkisi birçok çalışmada bildirilmiştir. Malikiwi ve ark. bizim çalıșmamıza benzer şekilde BPD tanılı bebeklerde tam enteral beslenmenin geciktiğini ortaya koydu (6). Bunun da düşük gestasyonel yaş ve doğum ağırlığı nedeniyle veya özellikle 2. haftanın sonuna doğru gelişmiş olan haPDA'nın bağırsak perfüzyonunu bozup beslenme intoleransına neden olmasıly açıklanabileceğini düşünmüşlerdir (9). Yine Wemhoner ve ark. (10) BPD tanılı bebeklerin yaşamlarının ilk iki haftasında daha az enteral beslendiğini ortaya koymuşlardır. Her ne kadar parenteral beslenme ile yeterli kalori ve protein intiyacı uygun şekilde kompanse edilmiş olup sağlansa da, BPD gelișiminin önlenmesi için enteral yolla verilmesi gereken makro ve mikronutrient desteğinin belli bir eşiği olduğunu düşündürmüştür (10).

Biz de orta-ağır BPD tanılı bebeklerde parenteral beslenmeden tam enteral beslenmeye geçiş sürecinin daha uzun sürmüş olabileceği, bu durumun datamenteral beslenmeningecikmesine ve bu dönemde yetersiz protein ve kalori alımına neden olmuş olabileceği hipotezini kurduk. Bu geçiş dönemindeki beslenme araștırmacıların ilgisini çekmiș, bu periyodda özellikle yetersiz protein alımının ekstrauterin büyüme geriliği için bir risk faktörü olduğu çalıșmalarda ortaya konulmuştur (11). Bu bulgular ile uyumlu olarak yetersiz beslenme sonucunda yaşamın ilk dört haftasındaki büyüme kısıtllığının BPD için risk faktörü olduğu belirtilmiştir (12).

Düşük gestasyonel yaşın BPD için en kritik risk faktörü olması uzun suredir bilinen bir gerçek olmakla birlikte, prematürenin kendisinin mi yoksa prematüriteye neden olan faktörlerin mi BPD ile ilişkili olduğu hala açıklığa kavuşmamıştır (13). Kanaliküler evreden sakküler evreye geçmekte olan akciğerde, preterm doğuma sıklıkla eşlik eden intrauterin büyüme kısıtlığı, inflamasyon, enfeksiyon ve oksijen toksisitesi gibi etkenlerin de varlığıyla vasküler ve alveolar gelişim durmaktadır (13).

Çalışmamızda orta-ağır BPD tanılı 97 hastanın 49'unun (\%50) doğum odasında ileri canlandırma intiyacı olduğu gösterilmiștir. Regresyon analizinde orta-ağır BPD ile ilişkisi en güçlü değişkendir. Özellikle solunum desteği olmaksızın geçiş sürecini tamamlayamayan çok düşük doğum ağırlıklı bebeklerde, daha ilk solukla birlikte baro/volütravma ve oksijen hasarı olușturarak akut akciğer hasarı bașlamaktadır (14). Bu nedenledir ki güncel rehberler ilk solukta başlayan akciğer hasarlanması kaskadını azaltmaya yönelik entübasyondan kaçınılması, akciğer koruyucu stratejler olan nazal CPAP, minimal invaziv surfaktan ve kısıtlı oksijen sunumu gibi uygulamaların rutin hale gelmesini önermektedir (14). Çok düşük ve aşırı düşük doğum ağırlıklı olup doğum salonunda veya yoğun bakım izleminde ileri canlandırma alan bebeklerin dahil edildiği bir sistematik derleme ve metaanalizde, ileri canlandırmanın kronik akciğer hastalığı 
için predispozan bir faktör olmadığı ortaya konmuştur (15). Öte yandan bu çalışmada yenidoğan yoğun bakım ünitesinde ve doğum salonundaki canlandırma nedenleri farklı olabileceği, uygun çıkarım yapmak için bunların ayrı değerlendirildiği çalışmalara intiyaç olduğu vurgulanmıştır (15). Klinger ve ark. (16) da popülasyon bazlı 1663 BPD tanıı bebeğin dahil edildiği geniş bir seride, bizim çalışmamıza benzer şekilde doğum salonunda ileri canlandırmanın BPD ile güçlü bir şekilde ilişkili olduğunu öne sürmüşlerdir.

Çalışmamızda haPDA varlığının, orta-ağır BPD gelişimi için bir risk faktörü olduğu ortaya konmuştur. İlaveten, haPDA için iki veya daha fazla medikal tedavi alımı ve ligasyon yapılmasının BPD ile ilişkili olduğu gösterilmişse de, lojistik regresyon analizinde anlamlı bir ilişki ortaya konmadı. Bu araştırmacıların en çok ilgisini çeken konuların başında gelmektedir. BPD ile PDA varlığı, büyüklüğü/şant miktarı, süresi, tedavi edilip edilmeme durumu, medikal veya cerrahi tedavi uygulaması ve zamanlaması ilişkisi çok sayıda retrospektif ve prospektif kontrollü araştırmada sorgulanmıştır (17). BPD ile haPDA'nın ilişkili olduğu birçok çalışmada gösterilmesine rağmen, bu ilişkinin gerçek bir neden sonuç ilişkisi mi ya da PDA'nın BPD gelişimine neden olan klinik hastalı̆ın basit bir belirteci mi olduğu konusu hala tartışmalıdır (14). Bizim çalışmamızda haPDA ile BPD ilişkisi ortaya konmuştur. En güncel çalışmalar, medikal tedaviyi birinci haftadan sonraya ertelemenin artmış BPD ve BPD/ölüm ile ilişkili olduğunu göstermektedir (18). Öte yandan, Clyman ve ark. (19) PDA-TOLERATE çalışmasında orta-büyük PDA'da farmakolojik tedavi verilen grup ile konservatif olarak takip edilen hasta grubu arasında BPD insidansı açısından fark göstermemiştir.

Çalışmamızın en önemli kısıtlıı̆̆ı retrospektif bir çalışma olmasıdır. Nutrisyon detayları (örneğin toplam kalori, protein ve lipid alımı, mayi miktarı), haPDA tanı ve tedavisiyle ilgili (tanı-tedavi günü, şant büyüklügü, tedavi tipi ve dozu) verilerin olmayışı çalışmamızın en önemli kısıtlııklarından biridir. Ek olarak kontrol grubunda hafif BPD tanilı hastaların da olması sonuçlar üzerinde etki yaratmış olabilir.

Sonuç olarak bu tek merkezli beş ylllık geniş bir kohortta yapılan çalışmada doğum salonunda ileri canlandırma, düşük gestasyon haftası, haPDA ve gecikmiş tam enteral beslenme BPD ile ilişkili bulunmuştur. Ancak tam enteral beslenmeye geçiş süresi ve haPDA ile BPD ilişkisinin neden sonuç mu yoksa BPD'ye gidiş sürecindeki hastalık durumunun bir parçası olup olmadığının ortaya çıkarıması için, geniş çaplı prospektif randomize çalışmalara intiyaç olduğu düşünülmüştür.

\section{KAYNAKLAR}

1. Northway Jr WH, Rosan RC, Porter DY. Pulmonary disease following respirator therapy of hyaline-membrane disease. Bronchopulmonary dysplasia. N Eng J Med 1967;276:357-68.

2. Bancalari E, Jain D. Bronchopulmonary dysplasia: 50 years after the original description. Neonatology 2019;115:384-91.
3. Hwang JS, Rehan VK. Recent advances in bronchopulmonary dysplasia: pathophysiology, prevention, and treatment. Lung 2018;196:129-38.

4. Higgins RD, Jobe AH, Koso-Thomas M, Bancalari E, Viscardi RM, Hartert TV, et al. Bronchopulmonary dysplasia: executive summary of a workshop. J Pediatr 2018;197:300-8.

5. Jobe $A H$, Bancalari E. Bronchopulmonary dysplasia. Am J Respir Care Med 2001;163:1723-9.

6. Papile LA, Burstein J, Burstein R, Koffler H. Incidence and evolution of subependymal and intraventricular hemorrhage a study of infants with birth weights less than 1500 gm. J Pediatr 1978;92:529-34.

7. Neu J. Necrotizing enterocolitis: the search for a unifying pathogenic theory leading to prevention. Pediatr Clin North Am 1996;43:40932.

8. Bozkurt O, Alyamac Dizdar E, Bidev D, Sari FN, Uras N, Oguz SS. Prolonged minimal enteral nutrition versus early feeding advancements in preterm infants with birth weight $\mathrm{g}$ : a prospective randomized trial. J Matern Fetal Neonatal Med 2020;1-7.

9. Malikiwi Al, Lee YM, Davies-Tuck M, Wong FY. Postnatal nutritional deficit is an independent predictor of bronchopulmonary dysplasia among extremely premature infants born at or less than 28 weeks gestation. Early Hum Dev 2019;131:29-35.

10. Wemhöner A, Ortner D, Tschirch E, Strasak A, Rüdiger M. Nutrition of preterm infants in relation to bronchopulmonary dysplasia. BMC Pul Med 2011;11:7.

11. Miller M, Vaidya R, Rastogi D, Bhutada A, Rastogi S. From parenteral to enteral nutrition: A nutrition-based approach for evaluating postnatal growth failure in preterm infants. J Parenter Enteral Nutr 2014;38:489-97.

12. Ehrenkranz RA, Dusick AM, Vohr BR, Wright LL, Wrage LA, Poole WK. Growth in the neonatal intensive care unit influences neurodevelopmental and growth outcomes of extremely low birth weight infants. Pediatrics 2006;117:1253-61.

13. Hwang JS, Rehan VK. Recent advances in bronchopulmonary dysplasia: Pathophysiology, prevention and treatment. Lung. 2018;196:129-38.

14. Foglia EE, Jensen EA, Kirpalani H. Delivery room interventions to prevent bronchopulmonary dysplasia in extremely preterm infants. J Perinatol 2017;37:1171-9.

15. Shah PS. Extensive cardiopulmonary resuscitation for VLBW and ELBW infants: a systematic review and meta-analyses. J Perinatol 2009;29:655-61.

16. Klinger G, Sokolover N, Boyko V, Sirota L, Lerner-Geva L, Reichman B, Israel Neonatal Network. Perinatal risk factors for bronchopulmonary dysplasia in a national cohort of very-lowbirthweight infants. Am J Obstet Gynecol 2013;208:115.e1-9.

17. Willis KA, Weems MF. Hemodynamically significant patent ductus arteriosus and the development of bronchopulmonary dysplasia. Congenital Heart Dis 2019;14:27-32.

18. Clyman RI. Patent ductus arteriosus, its treatments, and the risks of pulmonary morbidity. Semin Perinatol 2018;42:235-42.

19. Clyman RI, Liebowitz M, Kaempf J, Erdeve O, Bulbul A, Hakansson S, PDA TOLERATE Trial Investigators. PDA-TOLERATE Trial: An exploratory randomized controlled trial of treatment of moderateto-large patent ductus arteriosus at 1 week of age. J Pediatr 2019;205:41-8. 